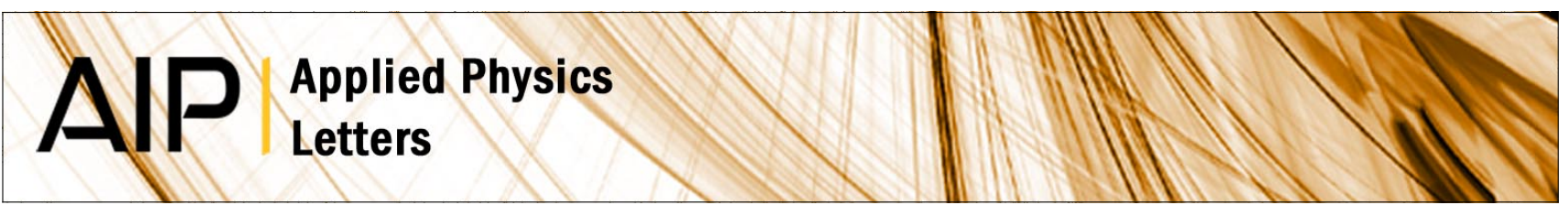

\title{
Doping screening of polarization fields in nitride heterostructures
}

Aldo Di Carlo, Fabio Della Sala, Paolo Lugli, Vincenzo Fiorentini, and Fabio Bernardini

Citation: Appl. Phys. Lett. 76, 3950 (2000); doi: 10.1063/1.126831

View online: http://dx.doi.org/10.1063/1.126831

View Table of Contents: http://apl.aip.org/resource/1/APPLAB/v76/i26

Published by the American Institute of Physics.

\section{Related Articles}

Thermal carrier emission and nonradiative recombinations in nonpolar ( $\mathrm{Al}, \mathrm{Ga}) \mathrm{N} / \mathrm{GaN}$ quantum wells grown on bulk GaN

J. Appl. Phys. 111, 033517 (2012)

Surface depletion mediated control of inter-sub-band absorption in GaAs/AIAs semiconductor quantum well systems

Appl. Phys. Lett. 100, 051110 (2012)

High-Q optomechanical GaAs nanomembranes

Appl. Phys. Lett. 99, 243102 (2011)

Mg-induced terahertz transparency of indium nitride films

Appl. Phys. Lett. 99, 232117 (2011)

Effect of metal-precursor gas ratios on AllnN/GaN structures for high efficiency ultraviolet photodiodes J. Appl. Phys. 110, 103523 (2011)

\section{Additional information on Appl. Phys. Lett.}

Journal Homepage: http://apl.aip.org/

Journal Information: http://apl.aip.org/about/about_the_journal

Top downloads: http://apl.aip.org/features/most_downloaded

Information for Authors: http://apl.aip.org/authors

\section{ADVERTISEMENT}

\section{Asrum

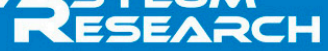
The Technology Leader in SPM/AFM

Register Now at www.asylumresearch.com

\section{Free AFM Webinar February 22 Register Now}

"Smaller and Quieter: Ultra-High Resolution AFM Imaging"

With Jason Cleveland, AFM pioneer, inventor and Asylum Research co-founder

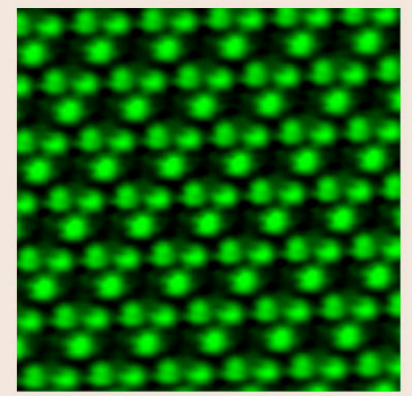




\title{
Doping screening of polarization fields in nitride heterostructures
}

\author{
Aldo Di Carlo, ${ }^{\text {a) }}$ Fabio Della Sala, and Paolo Lugli \\ INFM and Dipartimento di Ingegneria Elettronica, Università di Roma "Tor Vergata," I-00133 Rome, \\ Italy \\ Vincenzo Fiorentini and Fabio Bernardini \\ INFM and Dipartimento di Fisica, Università di Cagliari, I-09100 Cagliari, Italy
}

(Received 15 February 2000; accepted for publication 9 May 2000)

\begin{abstract}
Using self-consistent tight-binding calculations, we show that modulation doping can be used to screen macroscopic polarization fields in nitride quantum wells. The blue-shift of photoluminescence peak as well as the reduction of radiative recombination lifetime at increasing doping density is explained and correlated to polarization-field screening. The field-induced ionization of the dopants and its relation with alloy composition in the heterostructure barriers is also analyzed. (C) 2000 American Institute of Physics. [S0003-6951(00)05026-9]
\end{abstract}

Laser structures based on III-V nitride multiquantum wells (MQWs) have been shown to benefit from doping of the active region. ${ }^{1}$ However, several puzzles remain concerning the mechanisms involved. Experimentally, it has been established for both $\mathrm{GaN} / \mathrm{InGaN}^{2-9}$ and $\mathrm{AlGaN} / \mathrm{GaN}^{10-12}$ heterostructures that doping of the active region produces (i) a blue-shift of the photoluminescence (PL) peak, (ii) an enhancement of the emission intensity, (iii) a reduction of the laser threshold current, (iv) a reduction of the carrier radiative recombination lifetime, and (v) a reduction of the Stokes shift between PL peak and the photoluminescence excitation (PLE) spectra. Based on phenomenological arguments, it has been suggested that the observed phenomena is due to (a) doping-enhanced growth quality of the active region, $3,4,8,11,13$ (b) doping screening of polarization fields, ${ }^{3,5,6,9}$ or (c) screening of potential fluctuations. ${ }^{4-6,8}$

Despite its relevance to laser design, the doping effect has been only marginally touched upon theoretically. ${ }^{9,14}$ In this letter we apply the self-consistent procedure outlined in Refs. 14-16 to AlGaN/GaN and GaN/InGaN MQW systems, investigating how piezoelectric and spontaneous ${ }^{14,17-19}$ polarization fields can be screened via $n$ - and $p$-type doping. Further, we consider the screening interplay of extrinsic and injected carriers, experimentally investigated in Ref. 6.

We solve the Schrödinger equation in the nearestneighbor $s p^{3} d^{5} s^{*}$ tight-binding (TB) basis, ${ }^{20}$ selfconsistently coupled with a one-dimensional (1D) Poisson equation accounting for polarization, doping, and free carriers. ${ }^{14-16}$ The macroscopic polarization in the alloys are obtained by Vegard interpolation of $a b$ initio values ${ }^{17}$ for the binary compounds. This procedure describes the interplay of polarization and dielectric, free-carrier, and doping screening in a fully self-consistent and nonperturbative way, with band structure accuracies typical of $a b$ initio methods. ${ }^{20}$ Optical properties are obtained via the Graf-Vogl theory ${ }^{21}$ without introducing additional fitting parameters. The method has been previously employed to describe wide-gap MQW and interface systems. ${ }^{14,15,19,22}$

We performed calculations at room temperature for

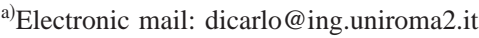

$\mathrm{Al}_{0.15} \mathrm{Ga}_{0.85} \mathrm{~N} / \mathrm{GaN}$ and $\mathrm{In}_{0.2} \mathrm{Ga}_{0.8} \mathrm{~N} / \mathrm{GaN}$ MQWs, with $100 \AA$ barriers and $40 \AA$ wells, pseudomophically grown on a GaN substrate. We considered purposely modulation-doped (doped barrier) structures, assuming a $10^{17} \mathrm{~cm}^{-3}$ residual doping in the wells. The extrinsic levels are chosen among a $20 \mathrm{meV}$ bound donor, and shallow $(20 \mathrm{meV})$ or deep (250 $\mathrm{meV}$ ) acceptors, the "deep" level representing typical $p$-dopants in $\mathrm{GaN} .^{23}$

The results for the AlGaN/GaN MQWs are shown in Fig. 1. The optical gap [the separation between the first quantized conduction $(\mathrm{C} 1)$ and valence $(\mathrm{V} 1)$ levels] and the $\mathrm{C} 1-\mathrm{V} 1$ oscillator strength (proportional to the $\mathrm{C} 1-\mathrm{V} 1$ radiative transition probability) are plotted respectively in Figs. 1(a) and 1(b) as a function of the doping density, for several values of an externally injected free carrier density $\left(n_{2 D}\right)$. Inclusion of the latter allows us to mimic lasing under electrical or optical pumping.

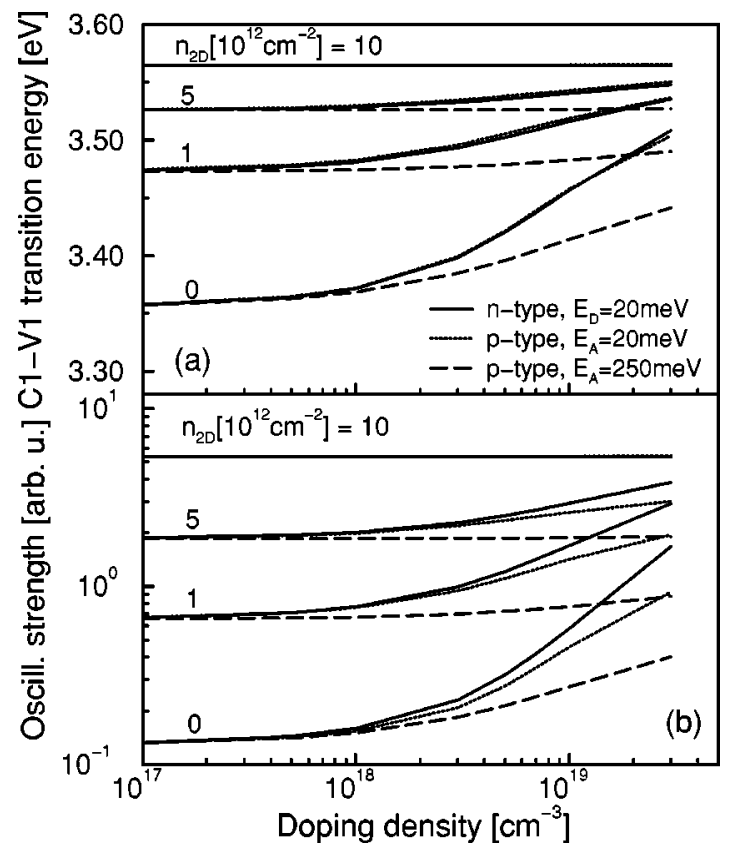

FIG. 1. Ground-level-emission transition energy (a) and oscillator strength (b) in $\mathrm{Al}_{0.15} \mathrm{Ga}_{0.85} \mathrm{~N} / \mathrm{GaN}$ MQWs, as a function of $p$ or $n$ doping densities, at different values of free-charge injection. 


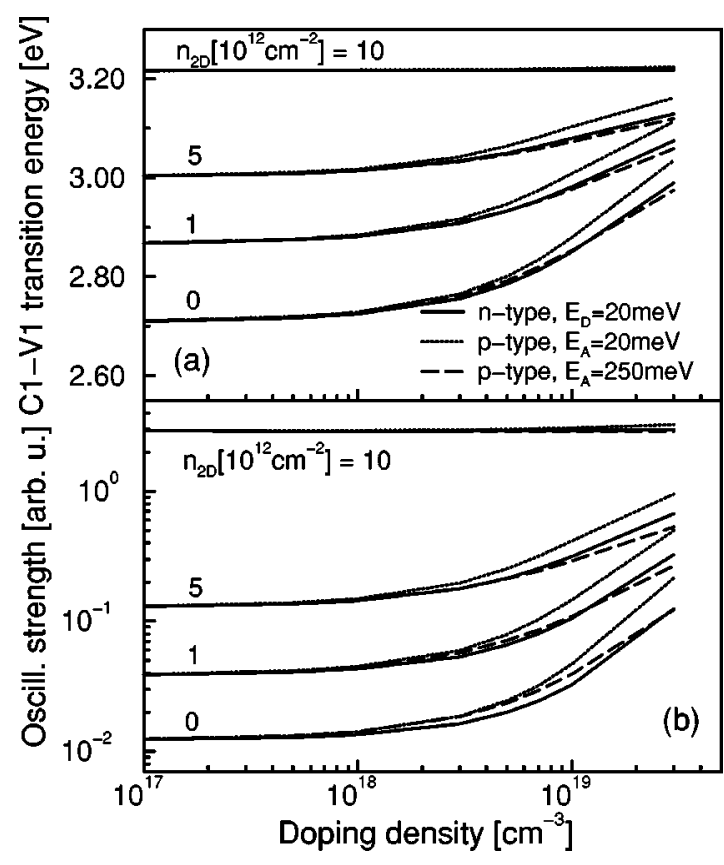

FIG. 2. As in Fig. 1, for GaN//n $n_{0.2} \mathrm{Ga}_{0.8} \mathrm{~N}$ MQWs.

At zero injection $\left(n_{2 D}=0\right)$, the extrinsic carriers from ionized dopants partially screen the macroscopic polarization field. For both $n$ - and shallow $p$-doping, the fundamental transition energy blue-shifts by as much as $150 \mathrm{meV}$ when the doping density is increased from $10^{17}$ to $3 \times 10^{19} \mathrm{~cm}^{-3}$ ). Deep (i.e., the actual) acceptors are much less efficient in screening the polarization and cause a blue-shift of only 80 $\mathrm{meV}$. Indeed, larger dopant binding energy implies fewer ionized centers, hence fewer free carriers in the well. Upon free-carrier injection, the doping-induced blue-shift is reduced. This is expected since screening is already activated by the injected free charge itself (notably at high injection).

The radiative probability of the $\mathrm{C} 1-\mathrm{V} 1$ transition [Fig. 1 (b)] is related to the laser threshold current. In the absence of carrier injection, the transition probability increases by an order of magnitude in going from low to high doping densities. In fact, doping screening of the field increases the overlap between confined conduction and valence states, enhancing the radiative transition probability. We found that the increase in transition probability is lower for shallow $p$ doping than for $n$ doping. This result depends on the different density of states and band offsets for electron and holes.

For laser operation, however, the case with injected carriers is more relevant. As for the transition energy, the higher the injected density, the smaller the doping-induced shift: at high injection, the polarization field is already screened even for low doping. However, for typical laser-operation densities, a moderately high doping does increase the transition probability. For $10^{19} \mathrm{~cm}^{-3}$ doping, one obtains the the same recombination probability at injection $n_{2 D}=5 \times 10^{12} \mathrm{~cm}^{-2}$ as at $n_{2 D}=10^{13} \mathrm{~cm}^{-2}$ with no doping. Since the recombination probability is inversely proportional to the spontaneous recombination lifetime, the laser threshold current will be reduced by proper doping design.

The doping dependence of transition energies and probability in GaN/InGaN MQWs is shown in Figs. 2(a) and 2(b), respectively. The overall effect of doping is stronger

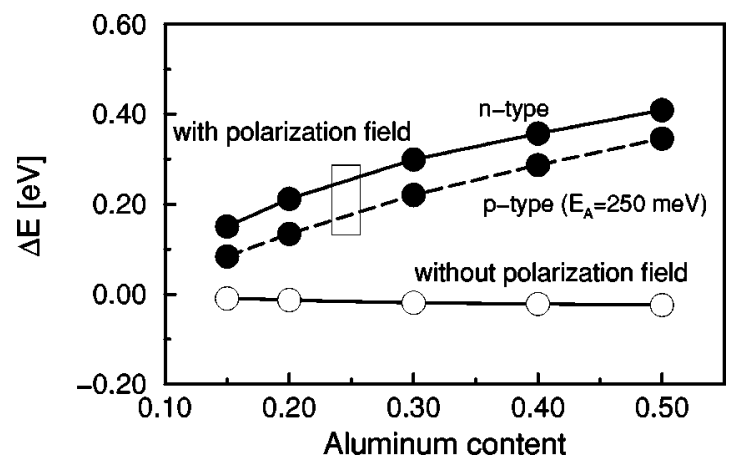

FIG. 3. Shift of the $\mathrm{C} 1-\mathrm{V} 1$ transition vs $x$ in $\mathrm{Al}_{x} \mathrm{Ga}_{1-x} \mathrm{~N} / \mathrm{GaN} \mathrm{MQWs}$, calculated as the difference of the $\mathrm{C} 1-\mathrm{V} 1$ transitions for doping levels of $3 \times 10^{19}$ and $10^{17} \mathrm{~cm}^{-3}$.

than in the $\mathrm{AlGaN} / \mathrm{GaN}$ case, the blue-shift amounting to $280 \mathrm{meV}$ for $n$ doping and for deep-level $p$ doping, and up to $325 \mathrm{meV}$ for shallow-level $p$ doping. The higher efficiency of doping screening in $\mathrm{GaN} / \mathrm{InGaN}$ wells is due to polarization field being larger than in $\mathrm{AlGaN} / \mathrm{GaN}$ ones (the polarization charge is $0.03 \mathrm{C} / \mathrm{m}^{2}$ at $\mathrm{GaN} / \mathrm{In}_{0.2} \mathrm{Ga}_{0.8} \mathrm{~N}$ interfaces, compared to $0.013 \mathrm{C} / \mathrm{m}^{2}$ at $\mathrm{Al}_{0.15} \mathrm{Ga}_{0.85} \mathrm{~N} / \mathrm{GaN}$ ones). The field-induced ionization (FII) of the dopant (already pointed out in Ref. 24) is consequently larger in the GaN/InGaN than the in $\mathrm{AlGaN} / \mathrm{GaN}$ structure. The FII effect is also responsible for the comparable effectiveness of the deep $p$ and $n$-type doping. Under high injection condition, the same trends are observed as in the $\mathrm{AlGaN} / \mathrm{GaN}$ case.

The degree of field ionization of the dopants in the barriers depends on the barrier material, via the alloy composition dependence of polarization fields. Hence, the screening efficiency should depend on composition. Indeed, consider Fig. 3, displaying the $\mathrm{C} 1-\mathrm{V} 1$ transition blue-shift obtained by raising the doping density from $10^{17}$ to $3 \times 10^{19} \mathrm{~cm}^{-3}$, as a function of $\mathrm{Al}$ concentration in the $\mathrm{AlGaN}$ barrier, and considering both $n$ and deep $p$ doping. The increased Al content enhances the electric field in the structure, hence the ionized dopant density: consequently the blue-shift is larger at large $\mathrm{Al}$ concentrations. Again, the deeper level screens less efficiently.

Neglect of polarization yields, as expected, a shift which is negligible on the relevant energy scale. This does not necessarily imply that the density of ionized impurities is reduced when polarization fields are neglected. While this is the case for $p$ doping because of the acceptor depth, ${ }^{24}$ it is not for $n$ doping, where the percentage of ionized dopants with and without polarization fields are comparable. As Fig. 4 shows, the key effect of the field is to ionize the impurities asymmetrically. The ionized (positive) centers and the electrons transferred into the well form a dipole which screens the field. If the field is zero, the ionization will be symmetric with respect to the quantum well, and no dipole will result.

In conclusion, we have shown that doping induces a blue-shift of the optical transition, larger for low injected carrier density. Doping increases the transition probability at the optical gap. This explains the experimental findings of lower laser threshold current, reduced radiative lifetime, and increased emission intensity in doped MQWs. Because of field ionization of the dopants, the doping screening efficiency depends on heterostructure composition. All free- 


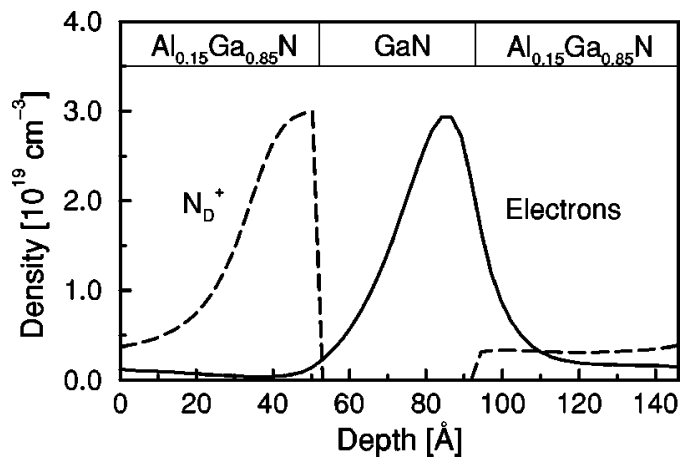

FIG. 4. Ionized dopant density (dashed lines) and electron density (solid line) in a $n$-doped $\left(3 \times 10^{19} \mathrm{~cm}^{-3}\right) \mathrm{Al}_{0.15} \mathrm{Ga}_{0.85} \mathrm{~N} / \mathrm{GaN}$ MQW.

charge related values (such as blue-shifts, PL intensity, Stokes-shifts, etc.) will thus depend both on doping and material composition. We conclude that doping is an additional degree of freedom to tune nitride lasers for efficiency.

Work supported in part by MURST, "Ultrafast Quantum Electronics" and "CLERMONT" UE Networks, and INFM through a PAISS Project.

${ }^{1}$ S. Nakamura, M. Senoh, A. Nagahama, N. Iwasa, T. Yamada, T. Matsushita, and H. Kiyoku, Appl. Phys. Lett. 70, 2753 (1997); S. Nakamura, M. Senoh, A. Nagahama, N. Iwasa, T. Yamada, T. Matsushita, H. Kiyoku, Y. Sugimoto, T. Kozaki, H. Umemoto, M. Sano, and K. Chocho, ibid., 72, 2014 (1998); 73, 832 (1998).

${ }^{2}$ P. A. Grudowski, C. J. Eiting, J. Park, B. S. Shelton, D. J. H. Lambert, and R. D. Dupuis, Appl. Phys. Lett. 71, 1537 (1997); S. Bidnyk, T. J. Schmidt, Y. H. Cho, G. H. Gainer, J. J. Song, S. Keller, U. K. Mishra, and S. P. DenBaars, ibid., 72, 1623 (1998).

${ }^{3}$ M. S. Minsky, S. Chichibu, S. B. Fleisher, A. C. Abare, J. E. Bowers, E. L. Hu, S. Keller, U. K. Mishra, and S. P. DenBaars, Jpn. J. Appl. Phys., Part 2 37, L1362 (1998).

${ }^{4}$ Y.-H. Cho, J. J. Song, S. Keller, M. S. Minsky, E. Hu, U. K. Mishra, and S. P. DenBaars, Appl. Phys. Lett. 73, 1128 (1998).

${ }^{5}$ T. Deguchi, A. Shikanai, K. Torii, T. Sota, S. Chichibu, and S. Nakamura, Appl. Phys. Lett. 72, 3329 (1998); S. Chichibu, D. A. Cohen, M. P. Mack, A. C. Abare, P. Kozodoy, M. Minsky, S. Fleisher, S. Keller, J. E. Bowers,
U. K. Mishra, 1. A. Coldren, D. R. Clarke, and S. P. DenBaars, ibid., 73, 496 (1998).

${ }^{6}$ J. Dalfors, J. P. Bergman, P. O. Holtz, B. E. Sernelius, B. Monemar, H. Amano, and I. Aksaki, Appl. Phys. Lett. 74, 3299 (1999).

${ }^{7}$ K. Uchida, T. Tang, S. Goto, T. Mishima, A. Niw, and J. Gotoh, Appl. Phys. Lett. 74, 1153 (1999).

${ }^{8}$ Y.-H. Cho, F. Fedler, R. J. Hauenstein, G. H. Park, J. J. Song, S. Keller, U. K. Mishra, and S. P. DenBaars, J. Appl. Phys. 85, 3006 (1999).

${ }^{9}$ H. Jiang, M. Minsky, S. Keller, E. Hu, J. Singh, and S. P. DenBaars, IEEE J. Quantum Electron. 35, 1483 (1999).

${ }^{10}$ A. Salvador, G. Liu, W. Ki, O. Aktas, A. Botchkarev, and H. Morkoc, Appl. Phys. Lett. 67, 3322 (1995).

${ }^{11}$ K. C. Zeng, J. Y. Lin, H. X. Jiang, A. Salvador, G. Popovici, H. Tang, W. Kim, and H. Morkoc, Appl. Phys. Lett. 71, 1368 (1997).

${ }^{12} \mathrm{H}$. Hirajama and Y. Aoyagi, MRS Internet J. Nitride Semicond. Res. 4S1, G3.74 (1999).

${ }^{13}$ S. I. Molina, A. M. Sanchez, F. J. Pacheco, R. Garcia, M. A. SanchezGarcia, F. J. Sanchez, and E. Calleja, Appl. Phys. Lett. 74, 3362 (1999).

${ }^{14}$ V. Fiorentini, F. Bernardini, F. Della Sala, A. Di Carlo, and P. Lugli, Phys. Rev. B 60, 8849 (1999).

${ }^{15}$ F. Della Sala, A. Di Carlo, P. Lugli, F. Bernardini, V. Fiorentini, R. Scholtz, and J. M. Jancu, Appl. Phys. Lett. 74, 2002 (1999).

${ }^{16}$ A. Di Carlo, S. Pescetelli, M. Paciotti, P. Lugli, and M. Graf, Solid State Commun. 98, 803 (1996); A. Di Carlo, Phys. Status Solidi B , 703 (2000).

${ }^{17}$ F. Bernardini, V. Fiorentini, and D. Vanderbilt, Phys. Rev. B 56, R10024 (1997); F. Bernardini and V. Fiorentini, ibid., 57, R9427 (1998).

${ }^{18}$ M. Leroux, N. Grandjean, M. Laugt, J. Massies, B. Gil, P. Lefebvre, and P. Bigenwald, Phys. Rev. B 58, R13371 (1998).

${ }^{19}$ R. Cingolani, A. Botchkarev, H. Tang, H. Morkoc, G. P. Traetta, G. Colì, M. Lomascolo, A. Di Carlo, F. Della Sala, and P. Lugli, Phys. Rev. B 61, 2711 (2000).

${ }^{20}$ J-M. Jancu, R. Scholz, F. Beltram, and F. Bassani, Phys. Rev. B 57, 6493 (1998).

${ }^{21}$ M. Graf and P. Vogl, Phys. Rev. B 51, 4940 (1995).

${ }^{22}$ G. Traetta, R. Cingolani, A. Di Carlo, F. Della Sala, and P. Lugli, Appl. Phys. Lett. 76, 1042 (2000); A. Bonfiglio, M. Lomascolo, G. Traetta, R. Cingolani, A. Di Carlo, F. Della Sala, P. Lugli, A. Botchkarev, and H. Morkoc, J. Appl. Phys. 87, 2289 (2000); A. Rizzi, R. Lantier, F. Monti, H. Lüth, F. Della Sala, A. Di Carlo, and P. Lugli, J. Vac. Sci. Technol. B 17, 1674 (1999).

${ }^{23}$ J. Neugebauer and C. van de Walle, in Advances in Solid State Physics (Vieweg, Braunschweig, 1996), Vol. 35, p. 25.

${ }^{24}$ P. Kozodoy, Y. P. Smorchkova, M. Hansen, H. Xing, S. P. DenBaars, U. K. Mishra, A. W. Saxler, R. Perrin, and W. C. Mitchell, Appl. Phys. Lett. 75, 2444 (1999). 